\title{
Dermatomyositis as a paraneoplastic phenomenon in ovarian cancer
}

\author{
Ilyas Arshad, Desmond Barton
}

Department of Gynaecology, The Royal Marsden Hospital, London, UK

\section{Correspondence to llyas Arshad, \\ ilyasarshad@gmail.com}

Accepted 23 June 2016

CrossMark

To cite: Arshad I, Barton D. BMJ Case Rep Published online: [please include Day Month Year] doi:10.1136/ bcr-2016-215463

\section{SUMMARY}

A 60-year-old woman diagnosed with papillary serous ovarian cancer had Klean-Prep and MRI contrast preoperatively. Afterwards, she developed swelling and an urticarial rash around her eye as she proceeded to have planned debulking surgery. Postoperatively the swelling and rash had spread over her face, neck, back and chest. Dermatology advised a possible allergy to Klean-Prep and MRI contrast. Subsequently over the next few months, the patient became severely debilitated from proximal myopathy of the upper and lower limbs, suffered severe pain restricting mobility and small bowel obstruction. Medical oncologist reviewed the patient, clinically diagnosed dermatomyositis and initiated treatment with high-dose intravenous steroids, resulting in remission of the patient's condition. The main purpose of this study is to describe the severity, diagnostic challenges and underline the clinical significance of dermatomyositis manifestations as a paraneoplastic effect in patients with ovarian cancer.

\section{BACKGROUND}

Dermatomyositis is rare and a difficult diagnosis to make.

Initially this case incorporates the diagnostic difficulty as to whether this patient had dermatomyositis and an allergy to Klean-Prep and MRI contrast.

Dermatomyositis may be more common than we believe; however, due to diagnostic difficulties, it may not be readily recognised and may be underdiagnosed. In this case, this resulted in a delay in diagnosis especially as the patient already had independent reasons for being unwell, namely, highgrade ovarian cancer, catabolic effects of major surgery and being immunocompromised. These may have blinded her diagnosis of dermatomyositis for a few weeks, allowing the dermatomyositis to progress in severity. Hence this is an important condition in which to raise public health emphasis and education to improve clinicians' diagnostic skills.

Using Ca-125 is not a sensitive test for screening ovarian cancer in populations with dermatomyositis.

Dermatomyositis can be very debilitating and distressing for patients. By making the diagnosis, an effective multidisciplinary team can be involved in the patients' management to formulate an effective treatment plan.

Balancing treatment with high-dose steroids in this patient can be concerning due to the increase in the stoma output as a result. There are also the added risks of electrolyte imbalances and immunosuppression, possibly affecting the rate of cancer recurrence.

\section{CASE PRESENTATION}

A 60-year-old woman, previously healthy patient, was referred for the consideration of curative surgery to maximally debulk her high-grade papillary serous ovarian cancer stage $3 \mathrm{~B}$. She was not known to have any allergies. This patient had a laparotomy, total abdominal hysterectomy, bilateral salpingo-oophorectomy, lymph node excision, posterior exenteration with rectosigmoid resection and defunctioning ileostomy. After having Klean-Prep and MRI contrast during the work-up for surgery, this patient developed an urticarial rash and swelling. She was seen by the dermatology consultant whose clinical impression was that she had an allergy to Klean-Prep.

Postoperatively the patient's condition deteriorated further, and her swelling and rash had spread over her face, neck, back and chest. This was extremely painful and debilitating for the patient. The pain from the rash over her face prevented the patient from wearing her reading glasses, as it was so severe. She proceeded to develop proximal myopathy of upper and lower limbs, resulting in severe pain that restricted mobility and small bowel obstruction. The medical oncologist reassessed this patient. A clinical diagnosis of dermatomyositis was made on the basis of the patient's history and also physical examination findings, including the presence of a heliotrope rash over the patient's periorbital skin, Gottron's papules over her metacarpophalangeal joints in association with weakness in swallowing in keeping with pharyngeal muscle weakness. Another dermatology consultation was requested. After reviewing the patient and excluding other causes such as systemic lupus erythematosus (SLE) and sarcoidosis with negative blood tests for anti-Jo-1, anti-Mi-2 and ANA autoantibodies, she was diagnosed with dermatomyositis. The chronicity and severity of these symptoms excluded this being an allergy to Klean-Prep and MRI contrast, as previously considered. At once, the patient was started on the treatment for dermatomyositis with high-dose intravenous hydrocortisone.

\section{INVESTIGATIONS}

Blood tests for anti-Jo-1, anti-Mi-2 and ANA autoantibodies were carried out. 


\section{DIFFERENTIAL DIAGNOSIS}

Tests for dermatomyositis, allergy to Klean-Prep/MRI contrast and SLE were carried out.

\section{TREATMENT}

Treatments included maximal debulking surgery and high-dose intravenous hydrocortisone.

\section{OUTCOME AND FOLLOW-UP}

This patient has been followed up for over 1 year and was diagnosed with dermatomyositis and treated with high-dose steroids. This helped the patient into remission.

\section{DISCUSSION}

The absence of reliable epidemiological data for dermatomyositis is rather surprising and may relate to several reasons: (1) the lack of a consistent use of diagnostic criteria, (2) the rarity of the disease, (3) the indolent clinical course and (4) the fact that the numbers result from studies on hospitalised patients only. ${ }^{1}$ The incidence of dermatomyositis varies from $0.5-0.89$ per $100000 .^{2}$ It is more commonly seen in malignancy as a study of 618 patients from Denmark suggests that 198 had an underlying malignancy (32\%) and 115 of the 198 patients were diagnosed with malignancy after first being diagnosed with dermatomyositis. ${ }^{3}$ Our patient had been seen by the dermatology team whose initial assessment concluded it a possible allergy to Klean-Prep and MRI contrast. The medical oncologist made the diagnosis due to disease progression and due to the history of swelling, painful rash, proximal upper and lower limb weakness in the context of the clinical examination, appearance of a heliotropic rash over the patient's periorbital skin, Gottron's papules over her metacarpophalangeal joints in association with weakness of the patient's proximal limb muscles and pharyngeal weakness.

Initially when the patient had swelling and a rash just prior to surgery, it was conceivable that this may be due to an allergy to Klean-Prep and MRI contrast. However, this became less likely as after the surgery the patient's condition deteriorated further, she started to develop more typical signs and symptoms pathognomonic for dermatomyositis. Dermatomyositis is a clinical diagnosis and carrying out a skin or muscle biopsy may be useful, however is not essential for diagnostic purposes, especially if clinical signs as mentioned above are present. In our case, the patient was undergoing much pain already and weak due to being postoperative after major surgery for high-grade cancer and having relapse of her dermatomyositis, the multidisciplinary team in consultation with the patient felt that a biopsy would be of more harm than benefit, especially as they were confident that she had dermatomyositis. Interestingly, the National Patient Safety Agency report the incidence of an allergy to Klean-Prep as being 1 in $218 .{ }^{4}$

Dermatomyositis can be debilitating and distressful for patients as it is complement mediated microangiopathy affecting skin and muscle with inflammation, containing a higher than normal percentage of B cells. Dermatomyositis may also be associated with a vasculitis involving the gastrointestinal tract. Eighteen to $32 \%$ of patients with dermatomyositis have an associated cancer, usually: breast, ovary, lung, pancreas, stomach, colon, rectum and non-Hodgkin's lymphoma. ${ }^{5}$ The association may be higher in those aged 40 years or older. Patients with dermatomyositis are advised to undergo malignancy screening during the first 3 years after the diagnosis of dermatomyositis, except for ovarian cancer that may present even 5 years following the diagnosis of dermatomyositis. Thus, patients are advised to Ca-125 testing every 6 months; however, screening for ovarian cancer with $\mathrm{Ca}-125$ in dermatomyositis has a sensitivity of $50 \% .{ }^{6}$ Skin and muscle disease may occur concurrently or independent of each other. ${ }^{7}$ In this case, the patient exhibited both. She had a painful rash over her face and scalp that precluded her from wearing glasses. She also had delay in oesophageal and gastric emptying, implying malfunction of the smooth muscle of the upper gastrointestinal tract; this resulted in

\section{Patient's perspective}

- I had started chemotherapy, and believing that reducing any residual cancer load would allow the dermatomyositis to recede, I continued a programme of paclitaxel and carboplatin. After about three treatments (out of a planned six), the oncologist advised a swift reducing programme for the steroids as there was concern about prolonged high-dose steroid therapy. Unfortunately, with the withdrawal of the steroids, dermatomyositis relapsed in a most alarming way. This time the skin ulceration covered my chest mainly, but the muscle weakness was most notable in the pharynx. I ceased to be able to swallow effectively, the right Eustachian tube blocked off and my speech was very weak. But most disabling of all, I had very little use of my hands.

- Accepting this relapse was probably the most distressing event of all that I had had to contend with. It also delayed the stoma reversal operation and managing life with the stoma was becoming more and more distressing for me.

- Of all the symptoms, one you have not mentioned, my facial and scalp skin meant that I could not wear reading glasses and the eye muscle weakness meant I had diplopia. But most disabling of all, I had very little use of my hands.

- Anyway, things are a lot better now and I am finally truly on the mend. However, to add to the story, my genetic status has been analysed and I have the BRCA1 mutation.

\section{Learning points}

- Dermatomyositis is rare with an incidence of $0.5-0.89$ per $100000 .^{1}$ It can be diagnosed clinically on history and examination findings. Pathognomonic examination findings include a heliotropic rash on the lateral surface of the eyelid and the presence of Gottron's papules. Eighteen to $32 \%$ of these patients will have an associated malignancy.

- Dermatomyositis can have profound effects on the skin and the muscle; in our case, it caused swelling and a painful rash on the skin and myopathy in upper and lower limbs, in addition to weakness in the pharyngeal muscles resulting in difficulties in swallowing.

- Dermatomyositis can be treated with high-dose intravenous steroids. It has been shown to improve with surgery and chemotherapy, when associated with a malignancy.

- The muscle weakness usually improves first, the rash may persist for longer.

- Worsening of the rash may be the first sign of relapse of malignancy and can be used in cancer surveillance. 
swallowing weakness and also functional small bowel obstruction. In addition, one of the most distressful symptoms for this patient was the weakness in her hands causing them to be of little use during relapse.

Our case highlights the need for clinical acumen in mapping the patient's history with clinical signs. The swelling and rash was painful and had spread over her face, neck, back and chest. In combination with the proximal myopathy of the upper and lower limbs, the patient became weaker and lethargic. Her stoma output decreased and she developed small bowel obstruction. She was managed with intravenous fluids, nasogastric tube, high-dose intravenous steroids, topical steroid preparation and Mepitel dressings for the weepy areas of her skin. The patient improved clinically. Dermatomyositis improved with surgery and chemotherapy; however, this is not always the case, as we experienced. Worsening of the skin rash may be the first sign of relapsing disease. Recognition of the risk of ovarian cancer $(13 \%)$ in the dermatomyositis population, particularly in women over 40, can expedite diagnosis and prognosis. ${ }^{8}$

Acknowledgements The authors thank the patient for allowing them to write this case as a case report to help for teaching and medical education purposes.

Contributors IA wrote the article. DB contributed to writing and editing this article.
Competing interests None declared.

Patient consent Obtained.

Provenance and peer review Not commissioned; externally peer reviewed.

\section{REFERENCES}

1 Dourmishev L, Dourmishev A. Dermatomyositis: advances in recognition understanding and management. Springer-Verlag, 2009.

2 Robinson $A B$, Reed AM. Clinical features, pathogenesis and treatment of juvenile and adult dermatomyositis. Nat Rev Rheumatol 2011;7:664-75.

3 Hill CL, Zhang Y, Sigurgeirsson B, et al. Frequency of specific cancer types in dermatomyositis and polymyositis: a population-based study. Lancet 2001:357:96-100.

4 National Patient Safety Agency. Reducing risk of harm from oral bowel cleansing solutions. http://www.medicinesresources.nhs.uk/upload/documents/Communities/ SPS_E_SE_England/NPSA_RRR_Supporting_Info_Oral_bowel_cleansing_preps_Feb_ 2009.pdf (accessed 21 May 2016).

5 Tsavaris $\mathrm{N}$, Karargyris $\mathrm{G}$, Pikazis $\mathrm{D}$, et al. Adenocarcinoma of the colon presenting as polymyositis: case report. J Chemother 2002;14:102-5.

6 Whitmore SE, Anhalt GJ, Provost TT, et al. Serum CA-125 screening for ovarian cancer in patients with dermatomyositis. Gynecol Oncol 1997;65:241-4.

7 Smith ES, Hallman JR, DeLuca AM, et al. Dermatomyositis: a clinicopathological study of 40 patients. Am I Dermatopathol 2009;31:61-7.

8 Christie A, McKay N, Nussey F. Dermatomyositis as presenting feature of ovarian cancer, treated with neo-adjuvant chemotherapy and interval debulking surgery. Gynecol Oncol Case Rep 2013;6:13-15.

\footnotetext{
Copyright 2016 BMJ Publishing Group. All rights reserved. For permission to reuse any of this content visit http://group.bmj.com/group/rights-licensing/permissions.

BMJ Case Report Fellows may re-use this article for personal use and teaching without any further permission.

Become a Fellow of BMJ Case Reports today and you can:

- Submit as many cases as you like

- Enjoy fast sympathetic peer review and rapid publication of accepted articles

- Access all the published articles

- Re-use any of the published material for personal use and teaching without further permission

For information on Institutional Fellowships contact consortiasales@bmjgroup.com

Visit casereports.bmj.com for more articles like this and to become a Fellow
} 